\title{
Low pH induces co-ordinate regulation of gene expression in oesophageal cells
}

\author{
Shane P.Duggan ${ }^{1, *}$, William M.Gallagher ${ }^{3}$, \\ Edward J.P.Fox ${ }^{3}$, Mohammed M.Abdel-Latif ${ }^{1,2}$, \\ John V.Reynolds ${ }^{2}$ and Dermot Kelleher ${ }^{1, *}$ \\ ${ }^{1}$ Department of Clinical Medicine and ${ }^{2}$ Department of Surgery, \\ Institute of Molecular Medicine, Trinity Centre for Health Sciences, \\ St James's Hospital, Dublin 8, Ireland and ${ }^{3}$ Department of Pharmacology, \\ Centre for Molecular Medicine, Conway Institute of Biomolecular and \\ Biomedical Research, University College Dublin, Dublin 4, Ireland \\ ${ }^{*}$ To whom correspondence should be addressed. \\ Tel: +35316082100; Fax: +35316083503; \\ Email: spduggan@tcd.ie or kellehdp@tcd.ie
}

The development of gastro-oesophageal reflux disease (GORD) is known to be a causative risk factor in the evolution of adenocarcinoma of the oesophagus. The major component of this reflux is gastric acid. However, the impact of low $\mathrm{pH}$ on gene expression has not been extensively studied in oesophageal cells. This study utilizes a transcriptomic and bioinformatic approach to assess regulation of gene expression in response to low $\mathrm{pH}$. In more detail, oesophageal adenocarcinoma cell lines were exposed to a range of $\mathrm{pH}$ environments. Affymetrix microarrays were used for gene-expression analysis and results were validated using cycle limitation and real-time RT-PCR analysis, as well as northern and western blotting. Comparative promoter transcription factor binding site (TFBS) analysis (MatInspector) of hierarchically clustered gene-expression data was employed to identify the elements which may co-ordinately regulate individual gene clusters. Initial experiments demonstrated maximal induction of EGR1 gene expression at pH 6.5. Subsequent array experimentation revealed significant induction of gene expression from such functional categories as DNA damage response (EGR1-4, ATF3) and cell-cycle control (GADD34, $G A D D 45$, p57). Changes in expression of EGR1, EGR3, $A T F 3, M K P-1, F O S B, C T G F$ and $C Y R 61$ were verified in separate experiments and in a variety of oesophageal cell lines. TFBS analysis of promoters identified transcription factors that may co-ordinately regulate gene-expression clusters, Cluster 1: Oct-1, AP4R; Cluster 2: NF-kB, EGRF; Cluster 3: IKRS, AP-1F. Low pH has the ability to induce genes and pathways which can provide an environment suitable for the progression of malignancy. Further functional analysis of the genes and clusters identified in this low pH study is likely to lead to new insights into the pathogenesis and therapeutics of GORD and oesophageal cancer.

\section{Introduction}

Over the past few decades, Western populations have witnessed a $10 \%$ annual increase in the incidence of oesophageal adenocarcinoma, whereas the incidence of oesophageal squamous carcinoma remains unchanged (1-3). Gastrooesophageal acid reflux has been identified in epidemiological studies as a major risk factor in the pathogenesis of oesophageal adenocarcinoma (4). Oesophageal adenocarcinoma commonly arises from the presence of a premalignant lesion known as Barrett's oesophagus (BO). This is a common condition in which normal squamous epithelium is replaced by a metaplastic intestine-like epithelium containing goblet cells $(2,5)$. Although the exact model for the development of BO has not been fully elucidated, the current paradigm indicates that it most commonly occurs in the setting of gastro-oesophageal reflux disease (GORD), in conjunction with as yet unidentified genetic and environmental factors (2,6-9).

The GORD refluxate consists of many different agents, such as stomach acid, bile acids (depending on the form of GORD), pepsins and gastrins (10), as well as metabolized oxidative products from the diet. As gastric acid is the major constituent of the reluxate and is postulated to be the cause of the initial inflammatory disease or oesophagitis, we focused our investigation on its modulatory role (11-13).

Previous work from our laboratory has demonstrated the ability of acidic or low $\mathrm{pH}$ conditions to induce proinflammatory signalling pathways, such as nuclear factorkappaB (NF-KB) transcription factor activation $(14,15)$. This activation is common in oesophageal adenocarcinoma where it inversely correlates with response to neo-adjuvant chemotherapy (14). It was of interest to expand the focus of this work to identify other transcriptional targets of low $\mathrm{pH}$ to provide further avenues for treatment. The early growth response gene 1 (EGRI) was an ideal candidate owing to its involvement in other inflammatory conditions and activation by carcinogens.

The EGR gene family of transcription factors encode nuclear proteins with zinc finger domains resembling those of the well characterized Sp1 transcription factor, which has been shown to have increased DNA binding activity under low $\mathrm{pH}$ conditions (16-18). There is increasing evidence for the involvement of EGRI in the regulation of immune response both in immune cells and epithelial cells $(19,20)$. EGRl is rapidly and transiently induced by many extracellular signals, such as growth factors, cytokines and phorbol esters, in a variety of cell types including fibroblasts, epithelial and endothelial cells $(21,22)$. In addition, $E G R I$ is induced by diverse types of DNA damaging agents and mild oxidative stress. We hypothesized that EGR 1 may be induced by low $\mathrm{pH}$ in the oesophageal cell lines SKGT4 and OE-33 and may lead to the identification of other related genes involved in low $\mathrm{pH}$ signalling. A novel bioinformatic approach for the comparative analysis of transcription factor binding sites (TFBSs) was used to analyse data 
derived from transcriptomic experiments. This identified distinct subsets of binding elements in the promoter regions that may co-ordinately control the transcription of particular gene clusters. In particular, the NF-KB and early growth response factor (EGRF) binding elements were identified as potentially important mediators in low $\mathrm{pH}$-based gene induction.

\section{Materials and methods}

Cells

OE-33 cells were obtained from the European Collection of Cell Cultures (Salisbury, UK) and maintained in culture with RPMI 1640 medium supplemented with $10 \%$ foetal calf serum, $100 \mathrm{U} / \mathrm{ml}$ penicillin, $100 \mu \mathrm{g} / \mathrm{ml}$ streptomycin and $2 \mathrm{mM} \mathrm{L}$-glutamine (Gibco BRL, Grand Island, NY) at $37^{\circ} \mathrm{C}$ in an atmosphere containing 5\% $\mathrm{CO}_{2}$. The SKGT4 cell line was obtained from Schrump et al. (National Cancer Institute, MD) (23) and cultured as above. HET-1A cells were purchased from the American Type Culture Collection (ATCC, Manassas, VA, USA) and cultured in bronchial epithelial basal media (BEBM) media with growth supplements (Cambrex Bioscience, Berkshire, UK). For western blot analysis, cells were seeded in 6-well plates at a density of $5 \times 10^{5}$ cells $/ \mathrm{ml}$ medium and grown to $80 \%$ confluence prior to experimentation. Cell viability was confirmed using acridine orange/ethidium bromide $(\mathrm{AO} / \mathrm{EB})$ and propidium iodide (PI) fluorescence staining (Sigma, Poole, UK). For gene-expression studies, $80 \mathrm{~cm}^{2}$ culture flasks were seeded with $\sim 5$ $\times 10^{6}$ cells in order to obtain sufficient RNA for northern blotting, RT-PCR and DNA microarray analyses. Acidic media was made by titrating RPMI (without serum at a temperature of $37^{\circ} \mathrm{C}$ ) with hydrochloric acid $(0.4 \mathrm{M})$ to the required $\mathrm{pH}$. Before acid treatment, SKGT4 cells were allowed to rest in serum-free media for $12 \mathrm{~h}$ before experimentation. No additive $\mathrm{pH}$ buffers were used; however, $\mathrm{pH}$ was monitored throughout the experiment and adjusted to within the range required. Resting control cells were mock titrated with equal volumes of water where required for each time point, to control for osmotic effects. RNA samples were taken after $\mathrm{pH}$ monitoring from the respective time points up to $4 \mathrm{~h}$ and at the same time as the appropriate time point controls. Experiments involving the HET-1A cell line were performed as above using BEBM media without the use of growth supplements.

Western blot analysis

Cells were lysed in $20 \mathrm{mM}$ Tris-HCL (pH 7.5), $1 \%$ SDS, $150 \mathrm{mM} \mathrm{NaCl}, 1 \mathrm{mM}$ EGTA, 1mM EDTA, $0.5 \mathrm{mM}$ PMSF and $10 \mu \mathrm{g} / \mathrm{ml}$ leupeptin (Sigma), followed by sonication and boiling. Protein extracts were resolved by SDSPAGE and transferred to PVDF membrane (Millipore, Bedford, MA). Blots were blocked with $5 \%(\mathrm{w} / \mathrm{v})$ dried skim milk in phosphate buffered saline (PBS) for $1 \mathrm{~h}$ at room temperature and then incubated for $1 \mathrm{~h}$ at room temperature with the primary polyclonal antibody to appropriate protein at a variable dilution in PBS/powdered milk. The immunoblots were then washed and incubated with an anti-rabbit, horseradish peroxidase-conjugated secondary antibody (DAKO, Bucks, UK). Immunodetection was accomplished by enhanced chemiluminescence.

RNA isolation and northern blot analysis

Total RNA was isolated using nucleospin extraction columns (Clontech, Palo Alto, CA) including a DNase step, while maintaining all samples on ice throughout the process. RNA samples $(5 \mu \mathrm{g})$ were run on $1.5 \%$ formaldehyde gels and integrity checked by UV transillumination. The RNA was transferred from formaldehyde gels to nylon membranes (Amersham Biosciences, Bucks, UK) by overnight capillary transfer. The membranes were cross-linked at $80^{\circ} \mathrm{C}$ for $2 \mathrm{~h}$ in an oven. Blots were checked for linear transfer by a methylene blue staining protocol (Sigma). Radiolabelled probes for northern blot analysis were prepared by PCR amplification of an appropriate region of the gene followed by incorporation of the labelled $\left[{ }^{32} \mathrm{P}\right] \mathrm{dCTP}$ nucleotide by random priming (Amersham, Aylesbury, UK). Templates for the probes were produced using the following primers: EGR-1 (forward 5'-CAGCTTGGTCAGTGGCCTAG-3' and reverse $5^{\prime}$ AATGTCAGTGTTCGGCGTG-3' from NCBI AJ24325) and GAPDH (forward 5'-CAGAACATCATCCCTGCCTCTAC- $3^{\prime}$ and reverse $5^{\prime}$-TTGAAGTCAGAGGAGACCACCTG- $3^{\prime}$ from NCBI J04038), synthesized by Invitrogen (Paisley, UK). Membranes were probed in Rapid-Hyb buffer (Amersham Biosciences) at $65^{\circ} \mathrm{C}$ overnight followed by washing with high stringency salt buffer.

Semi-quantitative RT-PCR analysis

Total RNA was isolated as above and was transcribed to cDNA using the RETROscript RT-PCR kit (Ambion, Huntingdon, UK). RNA (1 $\mu \mathrm{g})$ was reverse transcribed in a total volume of $20 \mu \mathrm{l}$. Of this cDNA reaction, $5 \mu \mathrm{l}$ was subjected to PCR amplification with SuperTaq (Ambion) using appropriate
Table I. RT-PCR primer sequences

\begin{tabular}{|c|c|c|}
\hline Gene & Forward primer & Reverse primer \\
\hline$M K P-1$ & 5'-GGTGATTTAGCGTCA-3' & $\begin{array}{l}5^{\prime} \text {-TGTGAAGGCAGA- } \\
\text { CACCTA-3' }\end{array}$ \\
\hline CTGF & $5^{\prime}$-GCTCCCTGCATCTTCGG-3' & $5^{\prime}$-GGCCCAACGGTTTG-3' \\
\hline EGR3 & $5^{\prime}$-ACCAACGAGAAGCCCAA-3' & $\begin{array}{l}5^{\prime} \text {-GGGGTCGTGGAA- } \\
\text { AGACA-3' }\end{array}$ \\
\hline$F O S B$ & $5^{\prime}$-ACCGTAGCTGAAGCTGA-3' & $\begin{array}{l}\text { 5'-ACTCGGCAGAG- } \\
\text { GGTGA-3' }\end{array}$ \\
\hline$A T F 3$ & $5^{\prime}$-CAAGAACGAGAAGCAGCA-3' & $\begin{array}{l}5^{\prime} \text {-CTGGGGCAGAAT- } \\
\text { GGGAA-3' }\end{array}$ \\
\hline
\end{tabular}

primers. Primers used for RT-PCR analysis were as detailed in Table I. Assessment of RT-PCR-derived products was performed via agarose gel electrophoresis at exponential points within respective reaction cycles.

\section{Real-time RT-PCR analysis}

Extraction of RNA and reverse transcription was performed as above. An aliquot of $1 \mu \mathrm{l}$ of the reverse transcription reaction was used in the realtime PCR reactions ( $20 \mu \mathrm{l}$ final volume) and performed in an ABI Prism 7700 thermocycler (Applied Biosystems, Foster City, CA). Primers for the genes (ATF3, EGR3, CYR61, DUSP5, MAN2C, MNT, C8FW) were obtained from the ABI 'Assay on Demand' website (http://home.appliedbiosystems.com/). Fold inductions were calculated using the cycle threshold $\Delta \Delta \mathrm{Ct}$ method as previously described $(24,25)$.

DNA microarray analysis

An aliquot of $10 \mu \mathrm{g}$ of total RNA from treated SKGT4 cells was reverse transcribed into single-stranded cDNA using the SuperScript Choice kit (Invitrogen, Paisley, UK). For this purpose, an oligo-dT primer containing a T7 RNA polymerase promoter (Genset) was utilized. Following double-stranded cDNA synthesis, biotin-labelled cRNA was generated by in vitro transcription using the BioArray RNA labelling kit (Enzo Diagnostics, Farmingdale, N.Y., USA). These complex cRNA targets, which are representative of the transcriptome of a particular sample, were hybridized against U133A arrays (Affymetrix, San Jose, CA). Detection was accomplished via a streptavidinlabelled fluorochrome (phycoerythrin) and laser scanning. The raw microarray data have been submitted to Gene Expression Omnibus for public access and may be obtained using the accession code GSE2144.

\section{Inter-array comparison of gene-expression data}

Normalization of data and inter-array comparisons of gene-expression profiles was carried out using Microarray Analysis Suite (MAS) version 5.0 (Affymetrix), together with Microsoft Access. In more detail, DNA microarray experiments were analysed using an approach based on the Mann-Whitney pairwise comparison test (26). To identify differentially expressed genes between any two samples, pairwise comparisons were performed using MAS. Lists of altered transcripts from different pairwise comparisons were sorted via Microsoft Access.

\section{Cluster analysis}

Detailed cluster analysis was performed using GeneSpring 4.0. Data were normalized initially by transforming the values $<0.001-0.001$. Each measurement was divided by the 50th percentile of all measurements in that sample. The percentile was calculated with all raw measurements $>0$ and using all genes not marked as absent. Each gene-expression value was divided by the median of its measurement in all samples. If the median of the raw values was $<0.01$, then each measurement for that gene was divided by 0.01 . Significantly altered genes were identified by viewing the data in the form of an ordered list of significance from which the top 100 were chosen for analysis. Guided analysis in the form of similarity searches were performed, followed by $k$ means clustering. These lists were then compared with more unguided methods, such as hierarchical clustering, before attempting to identify individual promoter clusters.

\section{Bioinformatic analysis of promoter regions}

Promoter regions for genes residing within clusters of interest were identified and retrieved via the use of Genome Browser housed at University of California Santa Cruz (http://genome.ucsc.edu/). Retrieved promoter regions (1500 bp upstream of the predicted start site) from collated clusters of genes were comparatively analysed using the TFBS analysis tool MatInspector (http://www.genomatix.de/) (27). The resultant list of TFBSs identified for each cluster were filtered against each other and against a cluster of randomly selected non-changing genes to give a list of the most significant TFBSs for each cluster. 


\section{Results}

Induction of EGRI mRNA by low pH in oesophageal cell lines $E G R l$ is an early growth response gene whose expression can be induced by many different stimuli including cytokines, growth factors, DNA damaging agents and oxidative stress. To examine EGRl expression under conditions of low $\mathrm{pH}$, SKGT-4 and OE-33 cells were treated with growth media whose $\mathrm{pH}$ had been altered with $0.4 \mathrm{M}$ hydrochloric acid. Figure 1A shows western blotting data for the induction of the $80 \mathrm{kDa}$ EGR1 protein under conditions of varying $\mathrm{pH}$ for $1 \mathrm{~h}$ in both SKGT4 and OE-33 oesophageal cell lines. The $\mathrm{pH}$ ranges between 7 and 6 , previously demonstrated to induce NF-KB (14), can clearly be seen to induce EGR1 protein expression. Induction of EGR1 mRNA was observed between $\mathrm{pH} 6.8$ and 6.2 in both cell lines when the $\mathrm{pH}$ range was focused (Figure 1B). At pH 6.5 (chosen to reflect gene induction midpoint), maximal induction of EGR1 was seen after $1 \mathrm{~h}$ (Figure 1C), which gradually returned to resting levels after $3 \mathrm{~h}$. This is mostly likely reflective of the increase in $\mathrm{pH}$ within the media over this time period. A system of $\mathrm{pH}$ monitoring was then used to maintain the $\mathrm{pH}$ within the range observed for EGRl gene induction (Figure 1C); in this case, the level of EGR1 mRNA expression was still increased up to $4 \mathrm{~h}$ postinitial treatment.

Identification of transcriptomic responses to conditions of low $\mathrm{pH}$

To further examine the effect of low $\mathrm{pH}$ conditions on a transcriptomic level, we employed DNA microarray-based
(A)

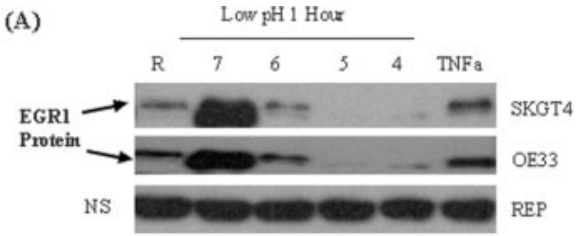

(B) Low pH 1 Hour

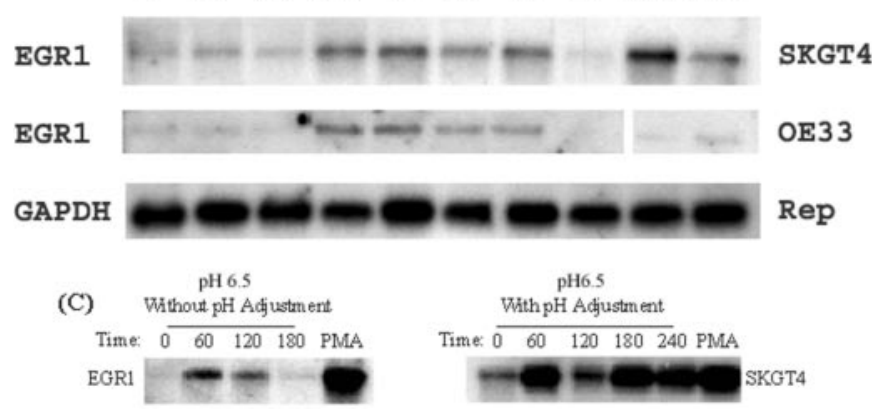

Fig. 1. Induction of EGR1 protein and mRNA by low pH in SGKT4 and OE-33 oesophageal cells. Levels of EGR1 mRNA and protein were determined by northern and western blot analysis, respectively. (A) Western blots from both oesophageal cell lines (SKGT4 and OE33) showing altered EGR1 protein expression in response to varying $\mathrm{pH}$ conditions over $1 \mathrm{~h}$. NS: Non-specific reference band. (B) EGR1 mRNA expression over a focused $\mathrm{pH}$ range in both cell lines (SKGT4 and OE33) as determined by northern blotting. (C) Time-dependent induction of EGR1 mRNA in SKGT4 cells stimulated with conditions of low $\mathrm{pH}$ with and without $\mathrm{pH}$ monitoring/adjustment (to maintain $\mathrm{pH}$ 6.5). Details the minutes following low $\mathrm{pH}$ treatment, with expression of EGR1 mRNA appearing transiently without $\mathrm{pH}$ maintenance and continuously with $\mathrm{pH}$ maintenance. PMA and $\mathrm{TNF} \alpha$ were used as positive controls for EGR1 induction. R signifies resting $\mathrm{pH}$ of 7.4 . gene-expression profile analysis. For this purpose, SKGT-4 cells were treated with low $\mathrm{pH}$ 6.5, together with $\mathrm{pH}$ monitoring, and analysed using Affymetrix U133A arrays, with $\sim 20000$ transcripts being examined in this respect. A range of genes were identified as being consistently differentially expressed in conditions of low $\mathrm{pH}$ as compared with the resting state, with the following number of transcripts being affected over time: 116 transcripts for $30 \mathrm{~min}, 480$ transcripts for $120 \mathrm{~min}, 115$ transcripts for $180 \mathrm{~min}$ and 741 transcripts for 240 min. Figure 2 details those genes whose expression was upregulated across all time periods in comparison with the resting state. Of note, EGRl was identified from the DNA microarray studies as being one of the significantly altered genes, providing initial validation for the methodology employed. Moreover, additional members of the early growth response gene family, EGR3 and EGR4, were induced by low $\mathrm{pH}$ conditions. Amongst the immune response genes, an increased expression of decay accelerating factor (DAF) was observed, which has previously been reported to be upregulated in BO (28). We also noted the expression of interleukin-8 (IL-8) and prostaglandin synthase (PTGS2 or COX2), both of which are upregulated in the Barrett's adenocarcinoma sequence (29-31). The transcription factors FOSB and JUN of the AP-1 transcription complex, known to have increased DNA binding potential under conditions of low $\mathrm{pH}$, are upregulated in the differentiation/proliferation group (Figure 2) (32). Many of the identified differentially expressed genes have functional roles in stress response, proliferation, differentiation, inflammation and growth arrest. Other important transcription factors identified using this approach are the Barrett's associated genes activating transcription factor 3 (ATF3) and nuclear receptor 4A2 (NR4A2) (33).

\section{Validation of gene-expression data}

A cohort of genes were chosen for downstream validation, varying from growth factors $(C T G F, C Y R 61, C 8 F W)$ to signalling molecules (MKP-1, DUSP5, MNT, EGR3, ATF3, $F O S B$ ). Changes observed in the DNA microarray studies of a subset of genes were confirmed by semi-quantitative RT-PCR analysis (Figure 3A). These included MKP-1, which was rapidly upregulated after $30 \mathrm{~min}$, and $C T G F$, which remained upregulated across the time periods. Additionally, ATF3 and EGR3 were validated by this method, showing rapid induction by $30 \mathrm{~min}$ increasing incrementally over time. Real-time RT-PCR analysis permitted examination of a much broader range of gene-expression changes (Figure $3 \mathrm{~B}$ and $\mathrm{C}$ ). GAPDH was used to normalize all genes in the real-time RT-PCR analysis including MAN2C, which was chosen from the array dataset as a non-changing gene to determine baseline fluctuations in the experimental approach. EGR3 and ATF3 have similar induction profiles with maximal induction at $2 \mathrm{~h}$, which may be indicative of similar transcriptional control mechanisms (Figure 3B). The FOSB gene was observed to be strikingly altered, with an $\sim 200$-fold increase in expression level observed at $120 \mathrm{~min}$ post-treatment as compared with that seen in the resting state (Figure 3B). Induction of EGR3 and ATF3 was also demonstrated on a protein level (Figure 3C). The importance of these genes in low $\mathrm{pH}$ signalling is highlighted by their responses in other oesophageal cell lines, such as OE-33 and the pre-neoplastic oesophageal cell line HET-1A (Figure 4). The oesophageal adenocarcinoma cell line OE-33 and the oesophageal squamous epithelial cell line HET-1A were treated with low pH 6.5 


\begin{tabular}{|c|c|c|c|c|}
\hline & $\begin{array}{l}\text { Mann } \\
\text { (Log }\end{array}$ & $\begin{array}{l}\text { Whitney } \\
\text { fold) }\end{array}$ & & Genespring \\
\hline 30 & 120 & 180 & 240 & \\
\hline 0.675 & 1.325 & 0.975 & 1.375 & \\
\hline .6 & 225 & 1.05 & 1.275 & \\
\hline 1.6 & 2.15 & 1.875 & 0.575 & \\
\hline 6 & 575 & 1.875 & 2.175 & 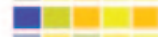 \\
\hline 0.925 & 0.475 & 0.975 & 1.075 & \\
\hline & 525 & 1. & 1.425 & E \\
\hline 3.15 & 1.15 & 2.25 & 2.475 & a \\
\hline 7 & & & 5 & E \\
\hline 3.625 & 2.05 & 3.8 & 75 & a \\
\hline 4 & 1.5 & 65 & 1.8 & - \\
\hline .05 & 1.225 & 1.4 & 1.725 & \\
\hline 925 & 0.775 & 1.2 & 25 & E \\
\hline 0.65 & 1.3 & 1.15 & 1.425 & \pm \\
\hline 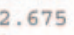 & 1.325 & 2 & 2.475 & $\square$ \\
\hline & 2.85 & 3.375 & 4.05 & \\
\hline 0.7 & & & & \\
\hline 0.67 & 275 & 0 & 27 & 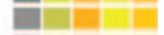 \\
\hline 1.075 & 2.05 & 1.4 & 1.575 & E \\
\hline & 1.6 & 1.125 & 1.275 & F \\
\hline 1.275 & 1.425 & 1.7 & 1.775 & 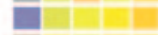 \\
\hline & & 1.0 & 1.0 & \\
\hline 1.2 & 1.425 & 1.625 & 1.95 & E \\
\hline & 1.3 & 5 & 1.69 & ㅁㅁ맘 \\
\hline \multirow[t]{2}{*}{0.45} & 1.575 & 1.35 & 2 & an \\
\hline & 1.2 & & & $=$ \\
\hline
\end{tabular}

Hs.283009 NM_020127205807_s_at Tuftelin 1 (TUFT1)

Hs.204354 NM 004040 $212099^{-}$at Ras homolog gene family, member B (RHOB)

Hs.51305 NM $012323205193^{-}$at $\mathrm{V}$-maf fibrosarcoma oncogene homolog $\mathrm{F}$ (MAFF) 36711 at

Hs.76556 NM_014330 202014_at

Apoptosis associated protein (GADD34) NM_014330 37028_at

Hs.171695 NM_004417 201041_s_at Dual specificity phosphatase 1 (DUSP1)

Hs. 326035 NM_001964 201693_s_at Early growth response 1 (EGR1)

Hs.74088 NM 004430206115 at Early growth response 3 (EGR3)

Hs.110571 NM $015675207574^{-} \mathrm{s}$ at Growth arrest and DNA-damage-inducible, beta (GADD45B) 209304 - x_at. 209305 s at.

Hs.80409 NM $001924203725^{-}$at Growth arrest and DNA-damage-inducible, alpha (GADD45A)

Hs.2128 NM_004419209457_at Dual specificity phosphatase 5 (DUSP5)

Hs.3052 NM_001965 207767 s_at Barly growth response 4 (EGR4)

Immune Response

Hs.179657 NM_002659 210845_s_at Uurokinase-type plasminogen activator receptor (PLAUR) 211924 s_at...

Hs.1369 NM_000574 201925_s_at Decay accelerating factor for complement (DAF) 201926 s at.

Hs.334924 NM_002309 205266_at Leukemia inhibitory factor (LIF)

Hs. 132004 NM $013246219500^{-}$at Cardiotrophin-like cytokine (CLC)

Hs.624 NM $000584202859^{-} \mathrm{x}$ at Interleukin \& $\mathrm{C}$-terminal variant (IL8)

Hs.82085 NM 000602 202628_s_at Serine proteinase inhibitor, clade B member 1 (SERPINBI) 202627 sat

Hs.196384 NM_000963 204748_at Prostaglandin-endoperoxide synthase 2 (PTGS2) Diff/Prolif

Hs.25497 NM_020310 204206 at MAX binding protein (MNT)

Hs.78465 NM $002228201466 \mathrm{~s}$ at $\mathrm{v}$-jun avian sarcoma virus 17 oncogene homolog (JUN) 201464_x_at. .

Hs.8867 NM_001554 210764_s_at cysteine-rich, angiogenic inducer, 61 (CYR61) $201289^{-1}$ at

Hs.270833 NM 001657205239 at

Hs.7837 NM_025195 202241_at

Hs.75511 NM 001901209101 at

Hs.75678 NM 006732202768 at

Hs. 283565 NM_005438 204420_at

Hs.75212 NM_002539200790_at

Hs.92186 NM_016201 203002 at

\section{Amphiregulin (AREG)}

Phosphoprotein regulated by mitogenic pathways (C8FW)

Connective tissue growth factor (CTGF)

FBJ murine osteosarcoma viral oncogene homolog B (FOSB) FOS-1ike antigen-1 (FOSL1)

Ornithine decarboxylase 1 (ODC1)

Leman coiled-coil protein (LCCP)

signalling

Hs.460 NM_001674 202672_s_at Activating transcription factor 3 (ATF3)

Hs.82101 NM 007350217997 at pleckstrin homology-1ike domain, family A, mem 1 (PHLDA1)

217996 at

Hs.77293 NM_014755 202657 s_at SERTA domain containing 2 (SERTAD2) 202656 sat.

Hs.171596 NM $004431203499^{\circ}$ at Homo sapiens EphA2 (EPHA2)

Hs.1119 NM $002135202340^{-} \mathrm{x}$ at Nuclear receptor subfamily 4, group A, member 1 (NR4A1)

Hs.82120 NM_006186 216248_s_at Nuclear receptor subfamily 4, group A, member 2 (NR4A2) 204621_s_at. $204622 \mathrm{x}$ at.

Other Functions 202267 at

Hs.5372 NM $001305201428^{-}$at

Hs. 12813 NM_015508 212665_at

213056 at

NM $005415 \quad 2019$

Hs. 153405 NM $^{-} 022817205251^{-}$at 208518 s at.

Hs. $213289 \mathrm{NM} 000527202068 \mathrm{~s}$ at Low density lipoprotein receptor (LDLR)

Claudin 4 (CLDN4)

DKFZP434J214 protein

FERM domain containing 4B, KIAA1013 (FRMD4B)

Solute carrier family 20 , member 1 (SLC20A1)

Period homolog 2 (PER2)

202067 sat. $\begin{array}{lllll}0.675 & 1.275 & 1.125 & 1.275\end{array}$

$\begin{array}{llll}1.675 & 1.275 & 1.975 & 2.15\end{array}$

$\begin{array}{llll}1.2 & 0.725 & 1.125 & 1.5\end{array}$

$\begin{array}{llll}2.325 & 2.55 & 2.6 & 3.075\end{array}$

$\begin{array}{llll}2.175 & 2.5 & 2.6 & 2.775\end{array}$

$\begin{array}{llll}1 & 1.8 & 1.3 & 1.6\end{array}$

$\begin{array}{llll}1.675 & 1.275 & 1.575 & 1.775\end{array}$

$\begin{array}{llll}2.075 & 2.4 & 2.45 & 2.45\end{array}$

$\begin{array}{llll}5.4 & 4.675 & 5.475 & 5.325\end{array}$

$\begin{array}{llll}1.9 & 2.975 & 2.8 & 2.95\end{array}$

$\begin{array}{llll}0.975 & 1.35 & 1.4 & 2.075\end{array}$

$1.05 \quad 1.25$

$\begin{array}{llll}3.325 & 1.6 & 3.325 & 3.65\end{array}$

$\begin{array}{llll}0.8 & 1.175 & 1.1 & 1.275\end{array}$

$\begin{array}{llll}0.825 & 1 & 1.05 & 1.15\end{array}$

$\begin{array}{llll}0.9 & 1.45 & 1.575 & 2.05\end{array}$

$\begin{array}{lll}0.925 & 1.225 & 1.5\end{array}$

$\begin{array}{lllll}0.675 & 0.525 & 0.725 & 0.625\end{array}$

$\begin{array}{llll}2.375 & 0.925 & 2.175 & 2.775\end{array}$

$\begin{array}{lllll}2.075 & 0.925 & 2.175 & 2.575\end{array}$

$\begin{array}{lll}2.05 & 2.225 \quad 2.5\end{array}$

$\begin{array}{llll}1.95 & 0.8 & 2 & 2.45\end{array}$

$\begin{array}{llll}1.4 & 1.6 & 1.5 & 1.85\end{array}$

$\begin{array}{lll}0.6 & 0.525\end{array}$

$\begin{array}{llll}1.3 & 2.45 & 1.95 & 1.975\end{array}$

$\begin{array}{llll}0.575 & 0.775 & 1.45 & 1.625\end{array}$

$\begin{array}{llll}1.2 & 1.325 & 1.425 & 1.45\end{array}$

$\begin{array}{llll}0.5 & 0.65 & 0.8 & 0.725\end{array}$

$\begin{array}{llll}0.95 & 0.675 & 1.175 & 1.05\end{array}$

$\begin{array}{llll}0.8 & 0.675 & 1 & 1.05\end{array}$

$\begin{array}{llll}0.75 & 1.15 & 0.875 & 1\end{array}$

$\begin{array}{llll}0.69 & 1.05 & 0.8 & 0.875\end{array}$

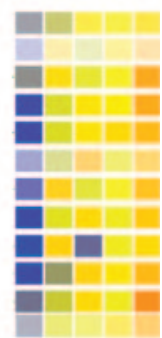

Fig. 2. Consistently upregulated genes induced by pH 6.5 in the transcriptome of SKGT4 oesophageal cells. Experiment as defined by the Mann-Whitney pairwise comparison test. Comparisons were made between resting state and various time points after treatment, with fold difference values (on a log scale) indicated to the right. Genes are grouped by functional category of the corresponding protein as defined by LocusLink/Entrez Gene and literature search, along with other standard identifiers, namely the relevant UniGene and GenBank accession codes, as well as the Affymetrix transcript code. Dots (..) represent independent probe set for the same transcript. Corresponding GeneSpring block view of each differentially expressed gene across the various time periods post-treatment is shown to the right. Blue represents low-expression levels, which move through a range of colours to red for high level of expression.

as before and gene expression was assessed using real-time RT-PCR analysis (Figure 4). Overall, the data confirm that the gene inductions observed are not cell line specific and are maintained to different degrees in cell lines of different malignant stages.

\section{Cluster analysis of DNA microarray data}

Similar expression profiles for $E G R 3$ and $A T F 3$ were observed using the GeneSpring software and the subsequent transcript and protein validation (Figure 3), indicating that these genes are under similar transcriptional control. In order to assess this 
(A)

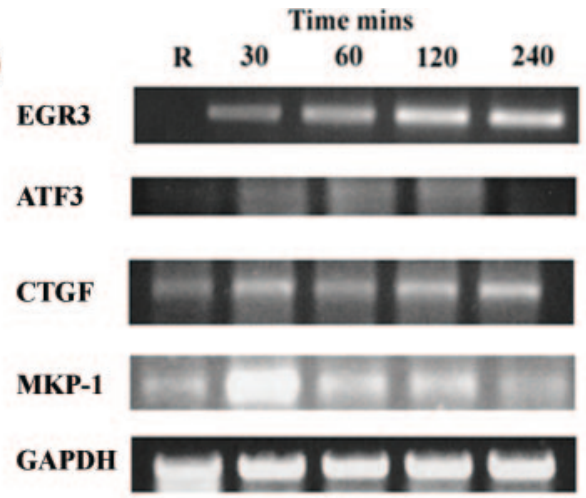

(B)

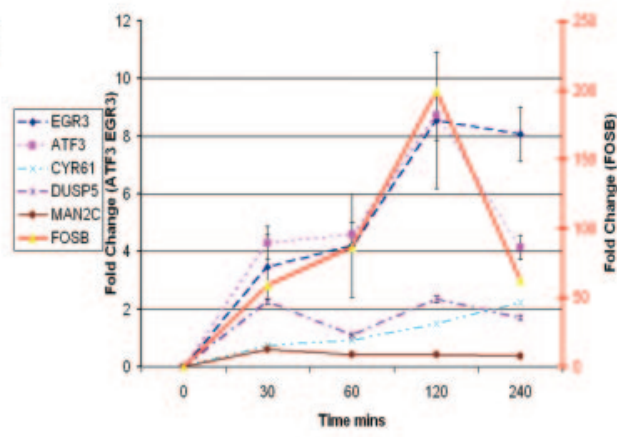

(C)

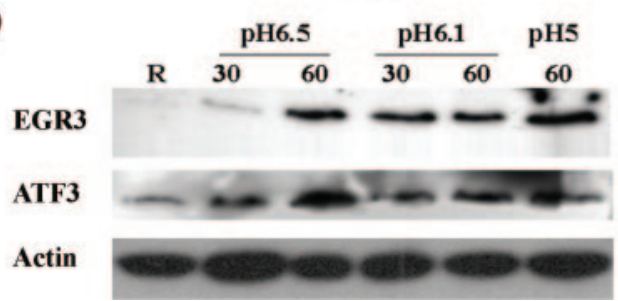

Fig. 3. Validation of DNA microarray data from the low $\mathrm{pH}$-induced transcriptome of SKGT4 oesophageal cells. Semi-quantitative (A) and real-time (B) RT-PCR analysis was used to examine the expression of indicated genes. In the context of real-time PCR analysis, fold changes for gene expression were calculated using the $\Delta \Delta \mathrm{Ct}$ method, with GAPDH being used as the internal control gene and resting cells as the calibrator. (C) Western blot analysis of ATF3, EGR3 and Actin (loading control) expression in SKGT4 cells under various $\mathrm{pH}$ conditions. $\mathrm{R}$ signifies resting $\mathrm{pH}$ of 7.4 .

possibility using promoter inspection software, it was necessary to identify distinct groups of profiles for comparison rather than one single profile. These profiles were obtained by clustering the top 100 most significantly altered genes as described by GeneSpring. Figure 5A details the unbiased hierarchical tree cluster of this ordered list, with three groups of genes identified and marked for in silico promoter analysis. We selected the three clusters for further promoter inspection based on the presence of verified and/or Barrett's related genes within the clusters.

Common regulatory elements within the promoter regions of individual clusters

A flow chart for the comparative promoter analysis is shown in Figure 5, beginning with the hierarchical tree and selected clusters in Figure 5A. Figure 5B details the expression profile of each of the clusters chosen for promoter analysis. Cluster 1 contains genes displaying a rapid increase in expression in response to low $\mathrm{pH}$, such as EGR3 and ATF3. Cluster 2 contains $C Y R 61$ and LDLR genes that reach maximal

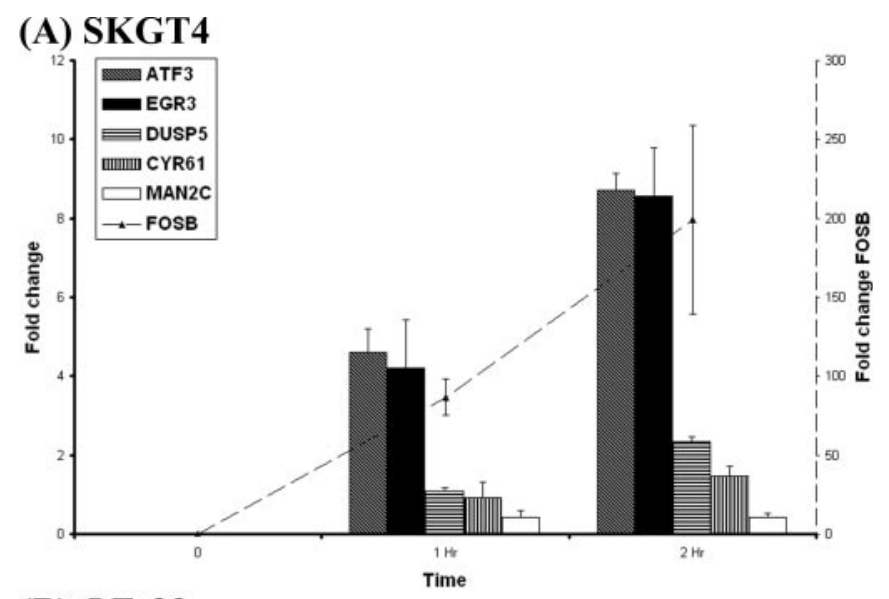

(B) OE-33

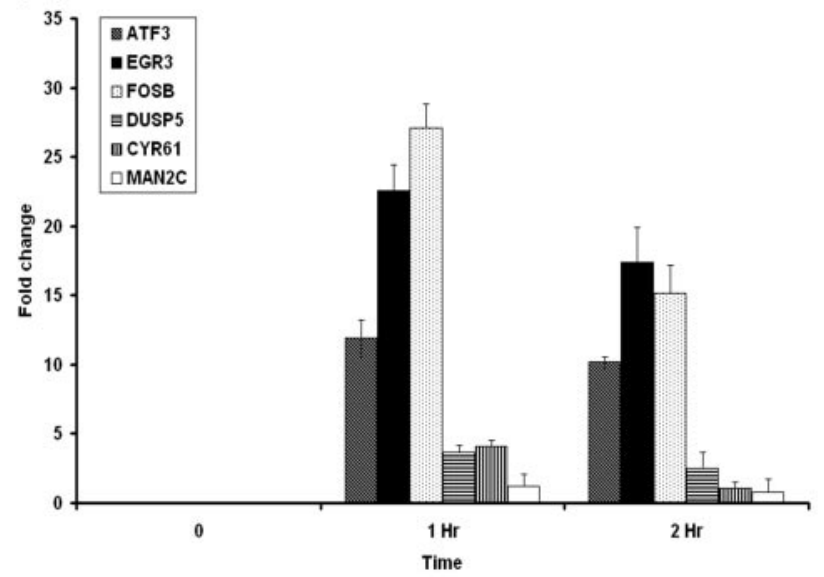

(C) HET-1A

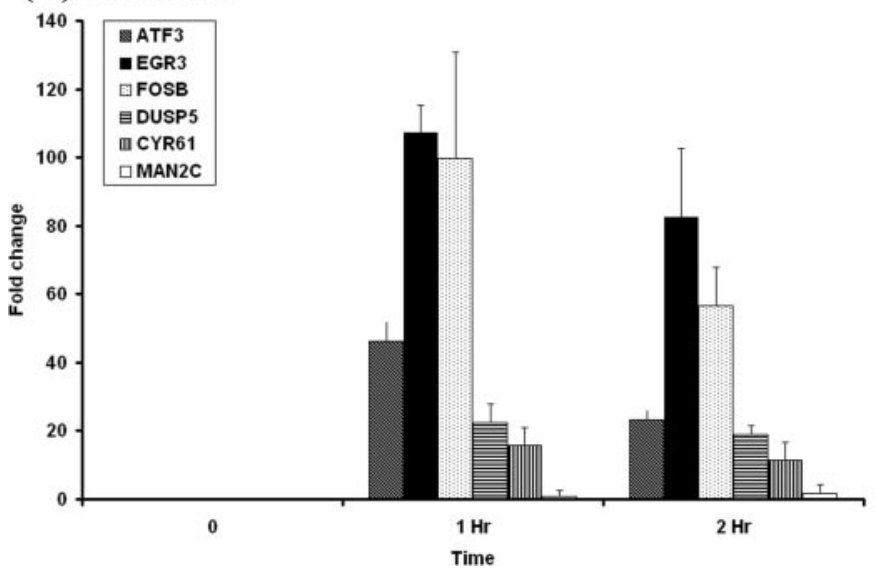

Fig. 4. Comparison of gene induction in the oesophageal adenocarcinoma cell lines SKGT4, OE-33 and squamous epithelial cell line HET-1A stimulated with low $\mathrm{pH}$ 6.5. Induction of mRNA was defined by real time RT-PCR in the oesophageal cell lines SKGT4 (A), OE-33 (B) and HET-1A (C). Fold changes for ATF3, EGR3, FOSB, DUSP 5, CYR61 and $M A N 2 C$ were calculated using the $\triangle \Delta \mathrm{Ct}$ method, with GAPDH being used as the internal control gene.

expression after $2 \mathrm{~h}$, whereas Cluster 3 includes genes of the metallothionein family which have a latent maximal expression at $4 \mathrm{~h}$. Promoter regions of the genes residing in the three clusters were examined for putative transcription factor binding sites which may co-ordinately regulate gene transcription. A fourth cluster of randomly selected nonchanging genes was also chosen as an internal control for 


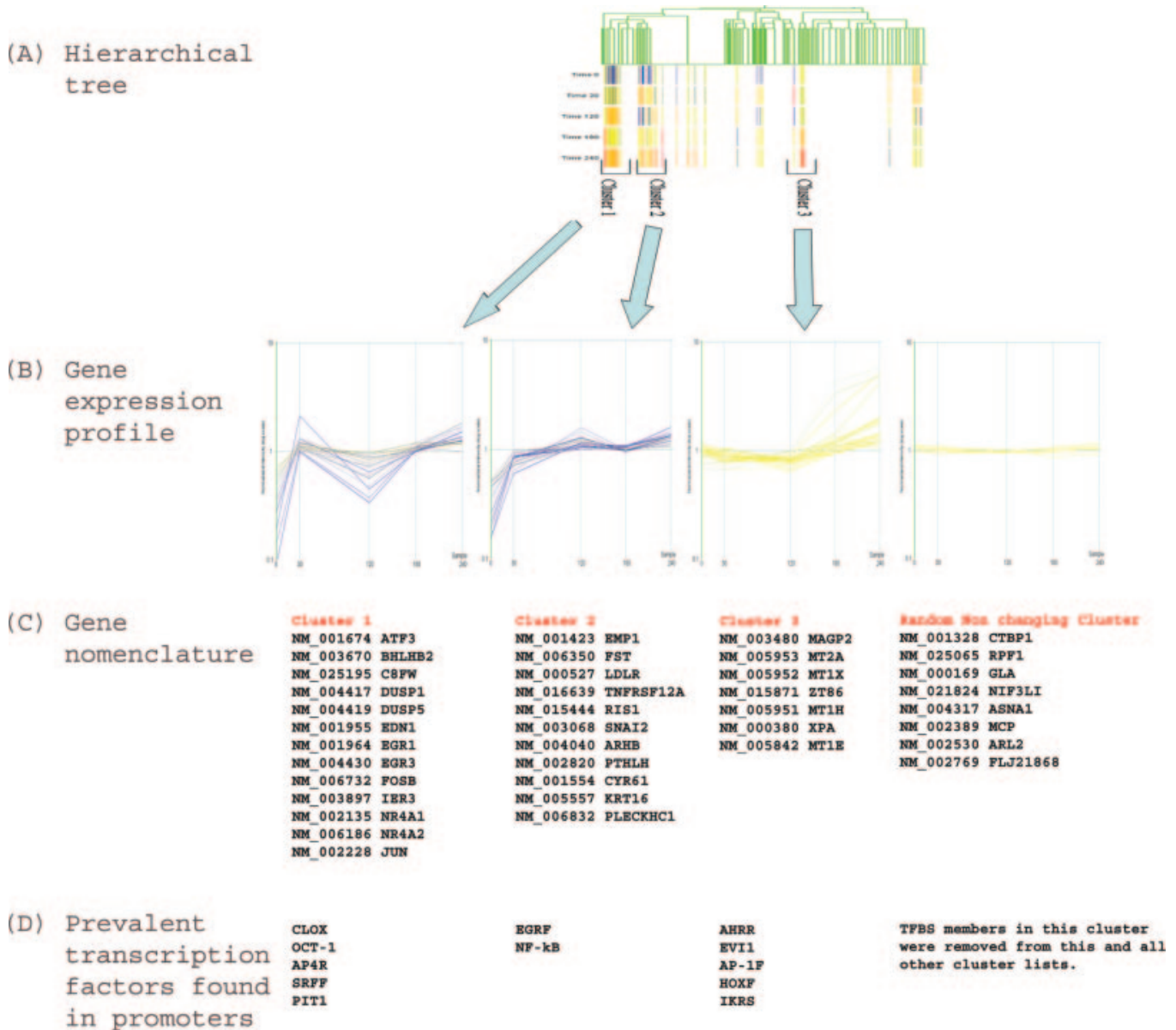

Fig. 5. Co-regulatory analysis of the low pH-induced transcriptome of SKGT4 oesophageal cells using the promoters of gene sets defined by hierarchical clustering. (A) Hierarchical clustering map of the genes in the ordered list. Gene-expression profiles have separated into distinct clusters. Blue represents low-expression levels, which move through a range of colours to red for high level of expression. Three gene-expression clusters have been marked for further bioinformatic analysis. (B) Expression profiles of each of the three clusters demonstrating the similarities of the genes within the individual clusters in comparison to a random selection of non-changing profiles. (C) Gene nomenclature of those genes chosen for promoter analysis from each cluster inclusive of the control, non-changing gene set. (D) Statistically significant TFBSs found within the majority of gene promoters within each individual cluster after comparison with the TFBS sets of the other clusters and the control non-changing gene set.

randomly occurring TFBSs. We identified the increased or significant occurrence of the binding sites within each cluster in comparison with each other and with the control set described. Figure 5C lists the genes residing within each of the cluster described and the most significant set of transcription factor binding elements found in their promoter regions is detailed in Figure 5D. Interestingly, Cluster 1 (EGR genes) may be controlled by the stress response factor Oct-1 and Cluster 2 by factors such as NF-KB and EGRF. Both NF-KB and AP-1 have been shown to have increased DNA binding potential under conditions of low $\mathrm{pH}(14,32,34)$. Furthermore, genes upregulated early in response to low $\mathrm{pH}$, such as those of the EGR family (Cluster 1), may be involved in the co-ordinate upregulation of the genes contained in Cluster 2 through the EGRF binding site identified. The co-ordinate relationship between the genes can be verified in correlation searches on the ATF3 gene using Oncomine 2.0 (35). Using the array data from Welsh et al. (36) prostate cancer study (oesophageal correlation not available), a correlation search was performed for the Barrett's related gene ATF3 (Figure 6) (33). A number of the co-regulated genes identified in this study (EGR3, $E G R I, F O S B, N R 4 A I)$ correlated highly with ATF3 expression, thus indicating that the clusters identified by this study may also occur in vivo.

\section{Discussion}

This study demonstrates that low $\mathrm{pH}$ induces a co-ordinate set of transcriptional responses in oesophageal cells, resulting in expression of genes involved in inflammation, stress response, proliferation and differentiation. This series of responses has been mapped to identify the impact of sequential transcriptional events. These findings identify genes induced by low $\mathrm{pH}$ which may be of potential importance in the pathogenesis of reflux oesophagitis and indirectly for the Barrett's cancer sequence.

The in silico transcription factor analysis applied in this study represents the first application of comparative binding site analysis to clustered data from a low $\mathrm{pH}$ gene induction study. Studies performed on cell lines with only one variable over time, i.e. low $\mathrm{pH}$, are ideal candidates for TFBS analysis. This method identified TFBS sets found in the promoter regions which may co-ordinately regulate the genes within the given clusters. The incorporation of an expression cluster consisting of randomly selected non-changing genes is a method whereby randomly occurring non-functional TFBSs may be controlled and eliminated from the analysis. The discovery of increased presence of both NF-KB and EGRF binding elements in the promoter regions of Cluster 2 is of major 


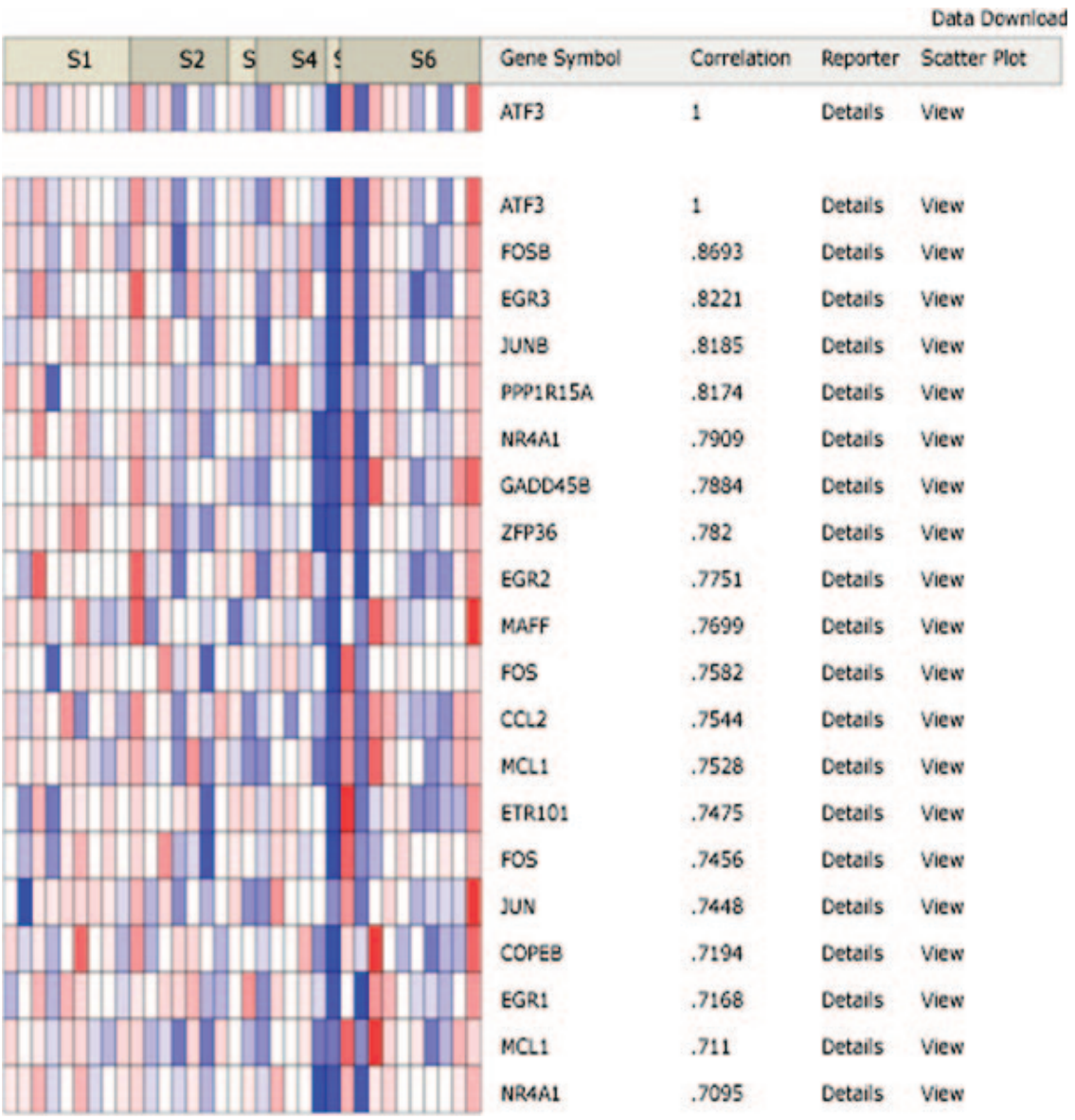

Fig. 6. Correlation searching in Oncomine cancer tissue database using ATF3 demonstrates in vivo relationships of genes identified in this study. Heat map of a correlation search for the gene ATF3 using the 'Welsh prostate array data' and the Oncomine 2.0 database. Detailing the similarity of gene-expression profiles to $A T F 3$ in numerous sets of microarray experiments performed on cancer tissue specimens.

interest for a number of reasons. The progress from GORD through to BO and adenocarcinoma passes through a gross inflammatory stage known as oesophagitis, and as with many other forms of inflammatory conditions can be characterized by the activation of the transcription factor NF-KB resulting in the expression of inflammation-related genes, such as $I L-8$ $(13,37)$. This master regulatory factor is also known to be upregulated in $\mathrm{BO}$ and overexpressed in $60 \%$ of oesophageal adenocarcinomas, where it inversely correlates with response to neo-adjuvant chemotherapy (14). Chromosome 4 on which NF-KB resides has also been shown to be amplified during oesophageal cancer progression (38-40). The above findings and previous reporting of NF-KB activation by low $\mathrm{pH}$ and bile acids lends weight to the importance of this transcription factor and its responsive genes in the progression of disease and as a potential therapeutic target. The promoters of Cluster 2 also contain the EGRF element which allows EGR1-4 to bind and activate transcription. This family of transcription factors are important inflammatory mediators and are often classed as oncogenes owing to their deregulation in many tumour types. EGR1, which is the most characterized member of the family can promote angiogenesis within tumour cores $(41,42)$. The low $\mathrm{pH}$ responsive genes EGRI and EGR3 identified in this study are members of the first expression cluster and this marks the beginning of what is termed a regulatory inference network $(43,44)$. Transcriptional ordering or regulatory network inference is an area of bioinformatics under development as our understanding of gene networks and promoter function grows. We believe the methods employed in this study can add to the tools available to analyse the vast amounts of data generated from transcriptomic experiments and assist in identifying sequential biological events. Further validation and dissection of this regulatory network using such techniques as chromatin immunoprecipitation will improve the current understanding of the relationship between promoter TFBSs and the genes they regulate.

In order to assess the effects of low $\mathrm{pH}$ on gene expression, we exposed oesophageal cells to a sustained change in $\mathrm{pH}$ over the period of the experiment rather than recapitulating the real-life scenario of intermittent brief exposures over a lifetime. We have previously shown in oesophageal and gastric cells that $\mathrm{pH} 6.5$ can activate NF-KB, a key mediator of inflammation and disease progression $(14,15)$, and the transcription factor EGR1 identified in this study. There have been other reports of AP-1 DNA binding activity at the $\mathrm{pH}$ ranges used in this study (32). Therefore, it was of interest to determine the genes downstream of these transcription factors induced by low $\mathrm{pH}$ conditions. Sustained exposure to $\mathrm{pH}$ levels $<6$ resulted in loss of induction of NF-KB and it would not have been possible to identify downstream effects of this transcription factor at lower $\mathrm{pH}$ levels (15). In addition, preliminary experiments (data not shown) demonstrated that continuous culture in $\mathrm{pH} 3.5$ led to a significant loss in cell viability as determined by PI staining and MTT assay and, as such, was not suitable for detailed molecular analysis of low $\mathrm{pH}$ signalling. 
The identification of $E G R I$ as a low $\mathrm{pH}$-responsive gene in oesophageal cells allowed for its use as a positive control gene in the subsequent set of transcriptomic experiments performed. The initial broad $\mathrm{pH}$ range used demonstrated EGR1 protein induction from $\mathrm{pH} 7$ to 6 ; however, when these experiments were performed on a transcriptional level with a more focused $\mathrm{pH}$ range, it was discovered that EGR1 transcript induction occurred between $\mathrm{pH} 6.8$ and 6.2. Therefore, our choice of $\mathrm{pH}$ 6.5 detailed previously was within the induction $\mathrm{pH}$ range for both EGR1 protein and mRNA. The analysis of the data generated from array experimentation was critically assessed using two methods, the Mann-Whitney protocol developed by Jin et al. (26), followed by complementary analysis using GeneSpring, thus revealing genes whose expression had been altered by low $\mathrm{pH}$ conditions.

Subsequent to the array experimentation, the low $\mathrm{pH}$ responsive genes identified were allotted into groups based on similarity in their function as described by literature searches. The data analysis identified a small subset of genes whose expression was downregulated but only by small fold changes that were deemed not statistically significant, hence their omission from Figure 2. The full dataset is available for assessment in the GEO repository (GSE2144). Interestingly, in this study the expression of two important phosphatases, DUSP1 and 5, are upregulated. These genes are detailed in the signalling group (Figure 2) and are capable of dephosphorylating members of the SAPK, p38, JNK and MAPK family thus inactivating the pathways. Their induction by low $\mathrm{pH}$ at an early time point is indicative of genotoxic stress, environmental stress and MAP kinase pathway activation as this pathway attenuates its own induction in a pulsatile fashion $(45,46)$. Although DUSP1 is found in the cytoplasm where it may inhibit activation of the JNK pathway and thereby inhibit apoptosis, DUSP5 resides in the nucleus and attenuates ERK activation $(47,48)$. The induction and validation of the phosphatases in this study in conjunction with other members of the dual specificity phosphatases found in other low $\mathrm{pH}$ signalling models (49) lend weight to the importance of this family of proteins in low $\mathrm{pH}$ signalling. The stimulation of $I L-8$, urokinase-type plasminogen receptor and prostaglandin synthase 2 (PTGS2 or COX2) by low $\mathrm{pH}$ allows the activation of the immune system which is often deregulated in many epithelial tumours and $\mathrm{BO}(13,37)$. The activation of these genes is a hallmark of NF-KB activity which in turn controls the activation of the inflammatory response to stressful injury $(13,40)$.

$\mathrm{DAF}$, a complement regulatory protein, is another gene in the immune response category (Figure 2) induced by low $\mathrm{pH}$ conditions in this study that has previously been used as a biomarker for specialized intestinal metaplasia type BO (28). Other documented transcriptional responses to low $\mathrm{pH}$ confirmed in this study to have potential differential expression in BO include CYR61, which is a recently discovered angiogenesis factor, and Amphiregulin, which is an EGF receptor ligand from the differentiation and proliferation category (Figure 2) (33). ATF3 and NR4A2 orphan receptor, from the signalling group are also associated with $\mathrm{BO}$ (33). The expression of ATF3, a member of the ATF/CREB subfamily of basic-region leucine zipper (bZIP) proteins, can be induced by a number of stimuli, such as TGF- $\beta$, TNF- $\alpha$, DNA damage and other stressful conditions (50). To date, this gene has been seen to perform many roles in the form of a transcriptional repressor, for example, the repression of the Id inhibitors of differentiation through such mediators as $\mathrm{Smad} 3$ (51). Induction of this gene by low $\mathrm{pH}$ conditions in all three oesophageal cell lines used is indicative of oxidative damage to DNA, which can occur over time in acidic environments $(50,52)$. The induction of some genes in both normal and adenocarcinoma cell types indicates that they may not be specific to the metaplasia $\rightarrow$ adenocarcinoma sequence, but it does not preclude their involvement in oesophageal inflammatory pathogenesis or carcinogenesis.

In conclusion, we have demonstrated that low $\mathrm{pH}$ conditions can alter the expression of genes with diverse functions which may have potential association with BO. Novel bioinformatic techniques identified regulators of low $\mathrm{pH}$ gene induction, such as NF-KB and EGRF and the clusters of genes that they potentially regulate. Therapeutic intervention targeting these transcription factors and/or their regulatory mechanisms may be used to complement existing therapies to halt the development and progression of $\mathrm{BO}$.

\section{Acknowledgements}

We thank Alison Murphy of the Conway Institute for technical assistance and Dr Siobhan Mitchell of the IMM for technical support. This grant was supported by Higher Education Authority (HEA) and the Program for Research in Third Level Institutions (PRTLI).

Conflict of Interest Statement: None declared.

\section{References}

1.McManus,D.T., Olaru,A. and Meltzer,S.J. (2004) Biomarkers of esophageal adenocarcinoma and Barrett's esophagus. Cancer Res., 64, 1561-1569.

2. Jankowski,J.A., Wright,N.A., Meltzer,S.J., Triadafilopoulos,G., Geboes,K., Casson,A.G., Kerr,D. and Young,L.S. (1999) Molecular evolution of the metaplasia-dysplasia-adenocarcinoma sequence in the esophagus. Am. J. Pathol., 154, 965-973.

3. Wijnhoven,B.P., Tilanus,H.W. and Dinjens,W.N. (2001) Molecular biology of Barrett's adenocarcinoma. Ann. Surg., 233, 322-337.

4. Lagergren,J., Bergstrom,R., Lindgren,A. and Nyren,O. (1999) Symptomatic gastroesophageal reflux as a risk factor for esophageal adenocarcinoma. N. Engl. J. Med., 340, 825-831.

5. Katz,P.O. (2004) Management of the patient with Barrett's esophagus: a continuing dilemma for the clinician. Rev. Gastroenterol Disord., 4, 49-59.

6. Eda,A., Osawa,H., Satoh,K., Yanaka,I., Kihira,K., Ishino,Y., Mutoh,H. and Sugano,K. (2003) Aberrant expression of CDX2 in Barrett's epithelium and inflammatory esophageal mucosa. J. Gastroenterol., 38, 14-22.

7. Tselepis,C., Perry,I., Dawson,C., Hardy,R., Darnton,S.J., McConkey,C., Stuart,R.C., Wright,N., Harrison,R. and Jankowski,J.A. (2002) Tumour necrosis factor-alpha in Barrett's oesophagus: a potential novel mechanism of action. Oncogene, 21, 6071-6081.

8. Riddell,R.H. (2005) The genesis of Barrett esophagus: has a histologic transition from gastroesophageal reflux disease-damaged epithelium to columnar metaplasia ever been seen in humans? Arch. Pathol. Lab. Med., 129, 164-169.

9. Jankowski,J.A., Harrison,R.F., Perry,I., Balkwill,F. and Tselepis,C. (2000) Barrett's metaplasia. Lancet, 356, 2079-2085.

10. Fitzgerald,R.C. and Abdalla,S. (2003) Gastrin-induced hyperproliferation in Barrett's esophagus. Gastroenterology, 125, 1921; author reply 1921-1922.

11. Fitzgerald,R.C., Omary,M.B. and Triadafilopoulos,G. (1997) Acid modulation of HT29 cell growth and differentiation. An in vitro model for Barrett's esophagus. J. Cell Sci., 110 (Pt 5), 663-671.

12. Fitzgerald,R.C., Omary,M.B. and Triadafilopoulos,G. (1998) Altered sodium-hydrogen exchange activity is a mechanism for acid-induced hyperproliferation in Barrett's esophagus. Am. J. Physiol., 275, G47-G55.

13. Van Der Woude,C.J., Kleibeuker,J.H., Jansen,P.L. and Moshage,H. (2004) Chronic inflammation, apoptosis and (pre-)malignant lesions in the gastrointestinal tract. Apoptosis, 9, 123-130. 
14. Abdel-Latif,M.M., O'Riordan,J., Windle,H.J., Carton,E., Ravi,N., Kelleher,D. and Reynolds,J.V. (2004) NF-kappaB activation in esophageal adenocarcinoma: relationship to Barrett's metaplasia, survival, and response to neoadjuvant chemoradiotherapy. Ann. Surg., 239, 491-500.

15. O'Toole,D., Abdel-Latif,M.M., Long,A., Windle,H.J., Murphy,A.M., Bowie,A., O'Neill,L.A.J., Weir,D.G. and Kelleher,D. (2005) Low pH and Helicobacter pylori increase nuclear factor kappa b binding in gastric epithelial cells: a common pathway for epithelial cell injury? J. Cell Biochem., [Epub ahead of print].

16. Torigoe,T., Izumi,H., Yoshida,Y., Ishiguchi,H., Okamoto,T., Itoh,H. and Kohno,K. (2003) Low pH enhances Sp1 DNA binding activity and interaction with TBP. Nucleic Acids Res., 31, 4523-4530.

17. Skerka,C., Decker,E.L. and Zipfel,P.F. (1995) A regulatory element in the human interleukin 2 gene promoter is a binding site for the zinc finger proteins Sp1 and EGR-1. J. Biol. Chem., 270, 22500-22506.

18. Berendji,D., Kolb-Bachofen,V., Zipfel,P.F., Skerka,C., Carlberg,C. and Kroncke,K.D. (1999) Zinc finger transcription factors as molecular targets for nitric oxide-mediated immunosuppression: inhibition of $I L-2$ gene expression in murine lymphocytes. Mol Med., 5, 721-730.

19. Abdel-Latif,M.M., Windle,H.J., Fitzgerald,K.A., Ang,Y.S., Eidhin,D.N., Li-Weber,M., Sabra,K. and Kelleher,D. (2004) Helicobacter pylori activates the early growth response 1 protein in gastric epithelial cells. Infect Immun., 72, 3549-3560.

20. McMahon,S.B. and Monroe,J.G. (1996) The role of early growth response gene $1($ egr-l) in regulation of the immune response. J. Leukoc. Biol., 60 , $159-166$.

21. Sukhatme,V.P., Cao,X.M., Chang,L.C. et al. (1988) A zinc fingerencoding gene coregulated with c-fos during growth and differentiation, and after cellular depolarization. Cell, 53, 37-43.

22. Sukhatme,V.P. (1990) Early transcriptional events in cell growth: the Egr family. J. Am. Soc. Nephrol., 1, 859-866.

23. Altorki,N., Schwartz,G.K., Blundell,M., Davis,B.M., Kelsen,D.P. and Albino,A.P. (1993) Characterization of cell lines established from human gastric-esophageal adenocarcinomas. Biologic phenotype and invasion potential. Cancer, 72, 649-657.

24. Heid,C.A., Stevens,J., Livak,K.J. and Williams,P.M. (1996) Real time quantitative PCR. Genome Res., 6, 986-994.

25. Gibson,U.E., Heid,C.A. and Williams,P.M. (1996) A novel method for real time quantitative RT-PCR. Genome Res., 6, 995-1001.

26. Jin,H., Yang,R., Awad,T.A. et al. (2001) Effects of early angiotensinconverting enzyme inhibition on cardiac gene expression after acute myocardial infarction. Circulation, 103, 736-742.

27.Quandt,K., Frech,K., Karas,H., Wingender,E. and Werner,T. (1995) MatInd and MatInspector: new fast and versatile tools for detection of consensus matches in nucleotide sequence data. Nucleic Acids Res., 23, 4878-4884.

28.Hiraoka,S., Mizuno,M., Nasu,J., Okazaki,H., Makidono,C., Okada,H., Terada,R., Yamamoto,K., Fujita,T. and Shiratori,Y. (2004) Enhanced expression of decay-accelerating factor, a complement-regulatory protein, in the specialized intestinal metaplasia of Barrett's esophagus. J. Lab. Clin. Med., 143, 201-206.

29. Kuramochi,H., Vallbohmer,D., Uchida,K. et al. (2004) Quantitative, tissue-specific analysis of cyclooxygenase gene expression in the pathogenesis of Barrett's adenocarcinoma. J. Gastrointest. Surg., 8, 1007-1016; discussion 1016-1017.

30. Kawabe,A., Shimada,Y., Soma,T., Maeda,M., Itami,A., Kaganoi,J., Kiyono,T. and Imamura,M. (2004) Production of prostaglandinE2 via bile acid is enhanced by trypsin and acid in normal human esophageal epithelial cells. Life Sci., 75, 21-34.

31. Shirvani,V.N., Ouatu-Lascar,R., Kaur,B.S., Omary,M.B. and Triadafilopoulos,G. (2000) Cyclooxygenase 2 expression in Barrett's esophagus and adenocarcinoma: Ex vivo induction by bile salts and acid exposure. Gastroenterology, 118, 487-496.

32. Shimokawa,N., Kumaki,I., Qiu,C.H., Ohmiya,Y., Takayama,K. and Koibuchi,N. (2005) Extracellular acidification enhances DNA binding activity of MafG-FosB heterodimer. J. Cell Physiol., 205, 77-85.

33. Barrett,M.T., Yeung,K.Y., Ruzzo,W.L., Hsu,L., Blount,P.L., Sullivan,R., Zarbl,H., Delrow,J., Rabinovitch,P.S. and Reid,B.J. (2002) Transcriptional analyses of Barrett's metaplasia and normal upper GI mucosae. Neoplasia, 4, 121-128.

34. Xu,L., Fukumura,D. and Jain,R.K. (2002) Acidic extracellular pH induces vascular endothelial growth factor (VEGF) in human glioblastoma cells via ERK1/2 MAPK signaling pathway: mechanism of low $\mathrm{pH}$-induced VEGF. J. Biol. Chem., 277, 11368-11374.

35. Rhodes,D.R., Yu,J., Shanker,K., Deshpande,N., Varambally,R., Ghosh,D., Barrette,T., Pandey,A. and Chinnaiyan,A.M. (2004) ONCOMINE: a cancer microarray database and integrated data-mining platform. Neoplasia, 6, 1-6.

36. Welsh,J.B., Sapinoso,L.M., Su,A.I., Kern,S.G., Wang-Rodriguez,J., Moskaluk,C.A., Frierson,H.F.Jr and Hampton,G.M. (2001) Analysis of gene expression identifies candidate markers and pharmacological targets in prostate cancer. Cancer Res., 61, 5974-5978.

37. Konturek,P.C., Nikiforuk,A., Kania,J., Raithel,M., Hahn,E.G. and Muhldorfer,S. (2004) Activation of NFkappaB represents the central event in the neoplastic progression associated with Barrett's esophagus: a possible link to the inflammation and overexpression of COX-2, PPARgamma and growth factors. Dig. Dis. Sci., 49, 1075-1083.

38. Croft,J., Parry,E.M., Jenkins,G.J., Doak,S.H., Baxter,J.N., Griffiths,A.P., Brown,T.H. and Parry,J.M. (2002) Analysis of the premalignant stages of Barrett's oesophagus through to adenocarcinoma by comparative genomic hybridization. Eur. J. Gastroenterol Hepatol., 14, 1179-1186.

39. Doak,S.H., Jenkins,G.J., Parry,E.M., D’Souza,F.R., Griffiths,A.P., Toffazal,N., Shah,V., Baxter,J.N. and Parry,J.M. (2003) Chromosome 4 hyperploidy represents an early genetic aberration in premalignant Barrett's oesophagus. Gut, 52, 623-628.

40. Jenkins,G.J., Harries,K., Doak,S.H., Wilmes,A., Griffiths,A.P., Baxter,J.N and Parry,J.M. (2004) The bile acid deoxycholic acid (DCA) at neutral pH activates NF-kappaB and induces IL-8 expression in oesophageal cells in vitro. Carcinogenesis, 25, 317-323.

41. Adamson,E.D. and Mercola,D. (2002) Egr1 transcription factor: multiple roles in prostate tumor cell growth and survival. Tumour Biol., 23, 93-102.

42.Krones-Herzig,A., Adamson,E. and Mercola,D. (2003) Early growth response 1 protein, an upstream gatekeeper of the p53 tumor suppressor, controls replicative senescence. Proc. Natl Acad. Sci. USA, 100, 3233-3238.

43. Haverty,P.M., Hansen,U. and Weng,Z. (2004) Computational inference of transcriptional regulatory networks from expression profiling and transcription factor binding site identification. Nucleic Acids Res., 32, 179-188.

44. Haverty,P.M., Frith,M.C. and Weng,Z. (2004) CARRIE web service: automated transcriptional regulatory network inference and interactive analysis. Nucleic Acids Res., 32, W213-W216.

45. Ryser,S., Massiha,A., Piuz,I. and Schlegel,W. (2004) Stimulated initiation of mitogen-activated protein kinase phosphatase-1 (MKP-1) gene transcription involves the synergistic action of multiple cis-acting elements in the proximal promoter. Biochem. J., 378, 473-484.

46. Barry,O.P., Mullan,B., Sheehan,D., Kazanietz,M.G., Shanahan,F., Collins,J.K. and O'Sullivan,G.C. (2001) Constitutive ERK1/2 activation in esophagogastric rib bone marrow micrometastatic cells is MEKindependent. J. Biol. Chem., 276, 15537-15546.

47. Mizuno,R., Oya,M., Shiomi,T., Marumo,K., Okada,Y. and Murai,M. (2004) Inhibition of MKP-1 expression potentiates JNK related apoptosis in renal cancer cells. J. Urol., 172, 723-727.

48. Small,G.W., Shi,Y.Y., Edmund,N.A., Somasundaram,S., Moore,D.T. and Orlowski,R.Z. (2004) Evidence that mitogen-activated protein kinase phosphatase-1 induction by proteasome inhibitors plays an anti-apoptotic role. Mol. Pharmacol., 66, 1478-1490.

49. Morgan,C., Alazawi,W., Sirieix,P., Freeman,T., Coleman,N. and Fitzgerald,R. (2004) In vitro acid exposure has a differential effect on apoptotic and proliferative pathways in a Barrett's adenocarcinoma cell line. Am. J. Gastroenterol., 99, 218-224.

50. Fan,F., Jin,S., Amundson,S.A. et al. (2002) ATF3 induction following DNA damage is regulated by distinct signaling pathways and overexpression of ATF3 protein suppresses cells growth. Oncogene, 21, 7488-7496.

51.Kang,Y., Chen,C.R. and Massague,J. (2003) A self-enabling TGFbeta response coupled to stress signaling: Smad engages stress response factor ATF3 for Id1 repression in epithelial cells. Mol. Cell., 11, 915-926.

52. Jolly,A.J., Wild,C.P. and Hardie,L.J. (2004) Acid and bile salts induce DNA damage in human oesophageal cell lines. Mutagenesis, 19, 319-324.

Received January 13, 2005; revised August 9, 2005; accepted August 12, 2005 